\title{
Breast necrosis: Calciphylaxis a rare cause
}

\author{
Joseph J Thornton MD, James Dolph MD
}

\begin{abstract}
JJ Thornton, J Dolph. Breast necrosis: Calciphylaxis a rare cause. Can J Plast Surg 2008;16(3):165-167.

Calciphylaxis is a small vessel vasculopathy characterized by significant calcium deposition in the vessel walls and tissue of renal failure patients. The process leads to progressive, painful, ischemic wounding. Management is generally medical; however, superinfection requires surgical intervention. A case of calciphylaxis of the breast is presented. Calciphylaxis of the breast is atypical - the wounds are usually located on the abdomen and thighs. A discussion of the process, its progression, identification and surgical management is presented. A case is made for appropriate debridement and vacuumassisted wound therapy.
\end{abstract}

\section{La nécrose du sein : La calciphylaxie, une cause rare}

\begin{abstract}
La calciphylaxie est une vasculopathie des petits vaisseaux caractérisée par d'importants dépôts calciques sur la paroi des vaisseaux et des tissus des patients atteints d'insuffisance rénale. Le processus entraîne des lésions évolutives, douloureuses et ischémiques. D'ordinaire, la prise en charge est médicale, mais la surinfection exige une intervention chirurgicale. Un cas de calciphylaxie du sein est présenté. La calciphylaxie du sein est atypique. En général, les lésions se situent sur le ventre et les cuisses. Un exposé du processus, son évolution, son dépistage et sa prise en charge médicale sont présentés. On insiste sur l'importance d'un débridement convenable et du traitement des lésions par pression négative.
\end{abstract}

Key Words: Breast; Calciphylaxis; Ischemic; Necrosis

Calciphylaxis is a small vessel vasculopathy with extensive calcification. It is seen most often in chronic renal failure patients on dialysis, and most often occurs in areas of higher fat deposition, such as the abdomen, buttocks and upper thighs.

Lesions initiate with inflammatory skin changes including erythema and induration. Later stages progress to grayish-black necrotic lesions that are typically very painful and often require significant pain management. Progression of the disease results in further necrosis and secondary infection that can lead to sepsis and even death (1). Occurrence of these lesions on the breast is uncommon and can be complicated by an early appearance mimicking inflammatory breast cancer with peau d'orange skin changes as the first clinical sign (2).

The typical patient with calciphylaxis-induced breast necrosis is a middle-aged, overweight woman with renal failure requiring dialysis. Comorbid conditions often include diabetes, disorders of calcium and phosphate metabolism leading to hypercalcemia, hyperphosphatemia and hyperparathyroidism. Anticoagulation with warfarin may contribute to calciphylaxis as well as states of malnutrition and protein $\mathrm{C}$ and $\mathrm{S}$ deficiency $(1,3)$.

\section{CASE PRESENTATION}

A 58-year-old Caucasian woman with an extensive medical history presented to her primary doctors with complaints of a progressive skin lesion, located on her left medial breast for nearly one year. It began first with colour changes with a woody feel, and had progressed to frank necrosis at the centre with indurated subcutaneous tissues surrounding the area (Figure 1).

The patient was hypertensive, diabetic and had atherosclerotic heart disease. She had undergone coronary artery bypass

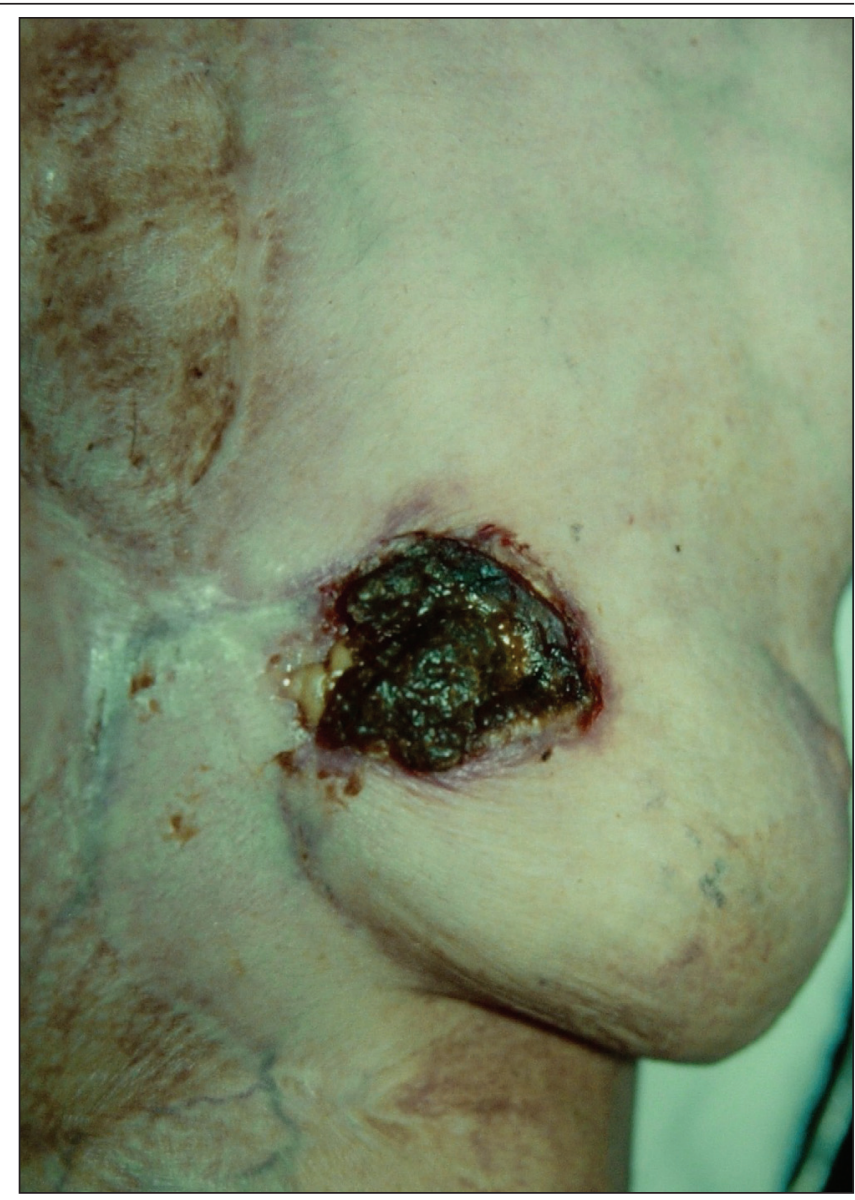

Figure 1) Initial presentation with central area of necrosis and infection 


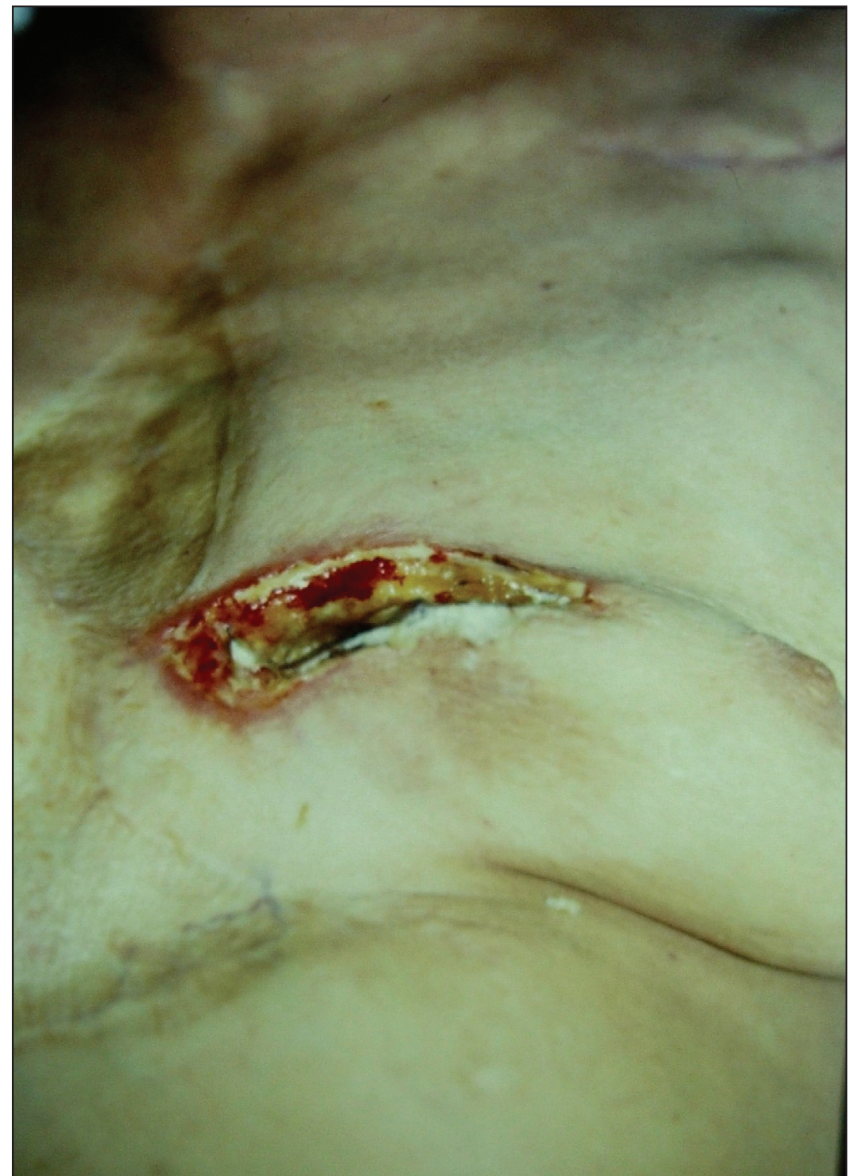

Figure 2) Immediately after resection of recurrent disease one month after initial closure

graft surgery seven years before presentation with harvest of the left internal mammary artery. A postoperative sternal wound infection was eventually treated by a right rectus abdominus muscle flap. Five years before presentation, chronic cellulitis on her left calf biopsied as calciphylaxis, prompting a parathyroidectomy to treat her symptomatic secondary hyperparathyroidism. Long-term use of warfarin for a deep vein thrombosis diagnosed eight years previously was ongoing.

The breast wound worsened with progressive necrosis and secondary infection requiring surgical intervention. In May 2004, the breast was debrided, resecting a $5 \mathrm{~cm} \times 8 \mathrm{~cm}$ area of indurated, hard tissue clinically consistent with calciphylaxis. Debridement of the lesion resulted in undermining of the breast; subsequently, an elongated skin incision was used to advance and close the breast wound primarily without tension. Cultures revealed methicillin-resistant Staphylococcus aureus, which was treated with vancomycin. In almost all cases after adequate debridement and appropriate antibiotics, a tensionfree closure would heal without incident. This is often not the case in patients with calciphylaxis.

At one-month follow-up, the incision demonstrated recurrent breakdown (Figure 2). The site was debrided and a vacuumassisted closure (VAC) device was applied. This stabilized the wound, which then granulated and contracted to final closure. Pathology of the first specimen revealed skin and subcutaneous tissue with significant ulceration and necrosis with minimal inflammation, along with calcified vessels on von Kassa stains. The second debridement demonstrated skin ulceration, fat necrosis and calcification; both specimens were consistent with calciphylaxis.

\section{DISCUSSION}

Calciphylaxis is an uncommon condition, especially with regard to the breast (4). One must be aware of its etiology and natural history, and treatment intent is often not to cure, but simply containment. Primary management is medical, with surgical debridement reserved for acute infections (5). Our case represents the problems of an ischemic wound: poor healing, breakdown, severe pain and prolonged course.

Longstanding renal insufficiency along with diabetes, obesity, previous hyperparathyroidism and warfarin use likely contributed to the process (1). Even though correction of the patient's hyperparathyroidism with parathyroidectomy in the past led to spontaneous healing of her leg and resolution of the calciphylaxis (2), this case demonstrates its potential for recurrence (1). The previous harvest of the left internal mammary artery at the time of the patient's coronary artery bypass graft surgery likely created a zone of relative hypoperfusion in the chest wall and breast, predisposing it to further breakdown (6).

Medical optimization is the recommended prevention and treatment for calciphylaxis. The mainstays of treatment are preventing renal failure, optimizing dialysis treatments, treating disorders of calcium, phosphate and parathyroid hormone, controlling diabetes and weight, maximizing nutritional status, limiting use of warfarin and recognizing those with protein C and $\mathrm{S}$ deficiencies (3). Furthermore, because ischemic lesions are often very painful, pain management may become the most important aspect of the patient's care.

If medical management fails, or the lesions become secondarily infected, surgical debridement must be performed. In classic, progressive cases, mortality is reported at rates of $80 \%$ and higher $(5,7)$. Debridement and control of infection is the goal of surgical therapy. Wound coverage options vary from healing by secondary intention to the use of skin grafts to local skin or muscle flaps. The VAC device may be a good choice in this population to simplify treatment, because progressive necrosis is common.

The painful 'die back' lesion encountered in such patients should prompt a complete medical history. Special note should be taken of renal failure, hyperparathyroidism, diabetes and warfarin use, because all of these may herald a diagnosis of calciphylaxis. Our patient did not suffer from renal failure even though she had a diagnosis of calciphylaxis. In the literature, renal failure and calciphylaxis go hand in hand (1-7); however, one must not be fooled by the absence of renal failure and overlook the possibility of calciphylaxis.

If calciphylaxis is probable, incisional biopsy can be performed to confirm the diagnosis and direct medical treatment (3). If operative treatment is unavoidable, it is important to remember that there is likely a systemic component to this vasculopathy. While adjacent tissues and structures may appear unaffected, surgical management of the wound with attempted closure can have severe consequences. Undermining, back cutting, or simply placing the adjacent tissues under tension during closure may lead to further necrosis and progression of the disease process. Open debridement and lavage of infected wounds is the mainstay of surgical treatment. Simple coverage is likely the best option in these complicated patients. Healing by secondary intention and skin grafting are classically performed; however, the wound VAC therapy is a promising 
option after debridement to enhance the healing process and simplify dressing care. This may, however, prove to be too painful for some patients. Calciphylaxis is a daunting problem, and prompt recognition and adherence to basic medical and surgical principles seem to help.

NOTE: No financial support was received for this paper.

\section{REFERENCES}

1. Wilmer WA, Magro CM. Calciphylaxis: Emerging concepts in prevention, diagnosis, and treatment. Semin Dial 2002;15:172-86

2. Patetsios P, Bernstein M, Kim S, Mushnick R, Alfonso A. Severe necrotizing mastopathy caused by calciphylaxis alleviated by total parathyroidectomy. Am Surg 2000;66:1056-8.
3. Oh DH, Eulau D, Tokugawa DA, McGuire JS, Kohler S. Five cases of calciphylaxis and a review of the literature. J Am Acad Dermatol 1999;40:979-87.

4. Kay PA, Sanchez W, Rose JF, Farley DR, Reynolds C. Calciphylaxis causing necrotizing mastitis: A case report. Breast 2001;10:540-3.

5. Kang AS, McCarthy JT, Rowland C, Farley DR, van Heerden JA. Is calciphylaxis best treated surgically or medically? Surgery 2000;128:967-71.

6. Rashid A, Haj Basheer M, Khan K. Breast necrosis following harvest of internal mammary artery. Br J Plast Surg 2004;57:366-8

7. Hafner J, Keusch G, Wahl C, et al. Uremic small-artery disease with medial calcification and intimal hyperplasia (so-called calciphylaxis): A complication of chronic renal failure and benefit from parthryoidectomy. J Am Acad Dermatol 1995;33:954-62. 